\title{
El pueblo Andino y su dialéctica histórica
}

\author{
Calixto Huanca Cárdenas*
}

\begin{abstract}
RESUMEN
Este artículo versa sobre la sociedad andina, vertido en dos realidades: la geográfica, socio-económica y la política, con el fin de analizar las razones de su contexto. Tal enfoque reviste un análisis de sus características fundamentales. Este nos conduce a replantearnos los conceptos de realidad geográfica, libertad, dominación, opresión, realidad económica, realidad política, entre otros.
\end{abstract}

Palabras clave: Pueblo andino, cultura, cultura aymara, cultura quechua, realidad geográfica, libertad, dominación, opresión, realidad económica, realidad política.

\section{ABSTRACT}

This article deals with the society andina, landfill in three realities; the geographical, socio-economic and policy. In order to analyze the reasons for its context. Such an approach is an analysis of its fundamental characteristics. This leads us to rethink the concepts of geographical reality, freedom, domination, oppression, economic, political reality, among others.

Keywords: Andean People, culture, Aymara culture, Quechua culture, geographical reality, freedom, domination, oppression, economic reality, political reality.

\section{Introducción}

La expresión "pueblo andino" es el punto de referencia de este artículo, cuya "armazón continental está constituida por la cordillera de los Andes, que sirve de elemento característico y definitivo" de dicha región (Cunill, 1978:24).

En este, intento analizar "El pueblo andino en el contexto histórico de La opresión y la liberación". Abordaremos dos aspectos claves importantes: A. La realidad geográfica, socio-económica y

Licenciado en Teología y filósofo. Tutor de la UNED y docente en la UCR. 
política y B. La realidad socio económica y política andina.

\section{Realidad geográfica}

Sobre la realidad geográfica andina, veamos cuatro momentos: Tiwanaku, Tawantisuyu, Colonial y actual.

El momento Tiwanaku es la época de las grandes culturas y civilizaciones milenarias del hombre andino, entre ellas la civilización arujaqi, pukina, chipaya, qulla Aymara de Tiwanaku y su irradiación luminosa de Chimú, Nazca. Chavín y Parakas que llegan a una transición con el imperio Inkaiku (Muzzo, 1910: 13-15). Gran parte de ellos se ubican frente al Océano Pacífico y la gran Cordillera de los Andes Centrales.

El momento de Tawantisuyu es la época de la civilización de la dinastía Inkaiku que comprende entre 1200 a 1532 d.C. El momento colonial es la época de los españoles (siglos XVI-XVIII). El territorio abarca el 75\% de Sur América.

El momento actual son las repúblicas independientes, que comprenden: Perú, Bolivia, Colombia, Venezuela, Ecuador y Chile. Es notable el espacio perdido por la influencia portuguesa.

Lo perteneciente a la geografía andina o sus linderos legítimos de desarrollo son: parte de Venezuela noreste, todo el Alto Amazonas, topando con el noreste boliviano, luego con la Argentina y hasta la desembocadura del río Maule de Chile al Océano Pacífico. En esta sección. P. Cunill en su obra La América Andina-Geografia Universal, hace un aporte valiosísimo (Cunill, 1978:23-71).

\section{Realidad socio-económica y política andina}

Se puede describir a partir de cuatro épocas, Tiwanaku, Tawantisuyu, la colonial y republicana de nuestros días. Estas cuatro épocas constituyen definiciones y características de "identidad-especificidad y diferencia" con realidades totalmente distintas (Fierro, 1979:15-76).

La época de Tiwanaku es distinta de las épocas que la siguen, tanto en su origen como en su realidad socio-económica y política.

Por su origen, se producen interrogantes y serias reflexiones en cuanto que el hombre americano sea originario de América o emigrante del viejo mundo. Sin embargo, de acuerdo con las investigaciones científicas, el origen del hombre andino aún es un misterio que se pierde en la niebla de la historia del pasado, porque tampoco es confiable que vino por el estrecho de Behring. Lo más probable es que el hombre andino tuvo su génesis en la "Paqariña Pacha", desde la ciudad milenaria telúrica de Tiwanaku y de allí se expandió a los cuatro puntos cardinales de América. Al respecto Posnansky sostiene: 
"América no es un nuevo mundo como nos ha sido enseñado por nuestros ex - amos los europeos, las Américas no han sido pobladas con la venida de un mísero elemento aportado por el estrecho de Behring o desde Oceanía, como muy sapientes e ilustres hombres de allende al océano alegan $y$ afirman con tanto afán. La misma edad que Europa y Asia tiene el género humano, la tiene también en las Américas y desde el mismo punto de donde ha inmigrado a las Américas; es decir, de la región donde generaron y revolucionaron de uno o más grupos pre-humanos, las dos razas primigenias." (Posnansky, 1945:91).

Además, para Posnansky, Tiwanaku tiene tres periodos importantes: Al primer periodo se le conoce como "Tiwanaku primitivo", de tiempo antiquísimo que no se ha llegado a calcular cronológicamente. El segundo periodo se logró calcular con el auxilio de estudios astronómicos en 15000 años de edad y el tercer periodo un poco menor a este tiempo. Al respecto, Posnansky refiere: "Lo que es en el punto de 15000 años a. de C. esta cifra constituiría la edad probable de Tiwanaku en el segundo periodo y de algo menos en el tercer periodo" (Posnansky, 1945:91).

Entre otros resultados de las investigaciones arqueológicas acerca del hombre andino y su origen, tenemos las recopilaciones de J. Alden Mason en "Periodos arqueológicos y culturales del Perú", que en resumen son: "la era incipiente comprende entre 8000 a 1250 años a. de C., la era de desarrollo entre 1250 a 300 a. de C., la era floreciente entre 300 a. de C., a 500 d. C., y la era climática entre 500 a 1532 años d. de C." (Mason, 1961:8).

La recopilación que hace Augusto Montenegro, respecto al desarrollo de la historia antes de la colonia española en América, también es sumamente importante. Él lo divide en cinco periodos:

"El lítico o paleoindio (40000 a.C.) Arcaico o preformativo (6000 a.C.) Preclásico o formativo (1500 a.C.) Clásico (300 d.C.) Posclásico (1300 d.C.)", (Montenegro, 1976:8).

Si a esto agregamos lo de Posnansky y de Mason, respecto al desarrollo del hombre andino, tendremos una mejor noción sistemática y cronológica del mismo (véase el cuadro aquí presentado).

Con mucha probabilidad podemos decir que el hombre americano tiene su génesis en la cultura más antigua del continente, "Tiwanaku.

Jean Cristian, escritor y científico de renombre, llega a conclusiones que expresa de esta manera: 


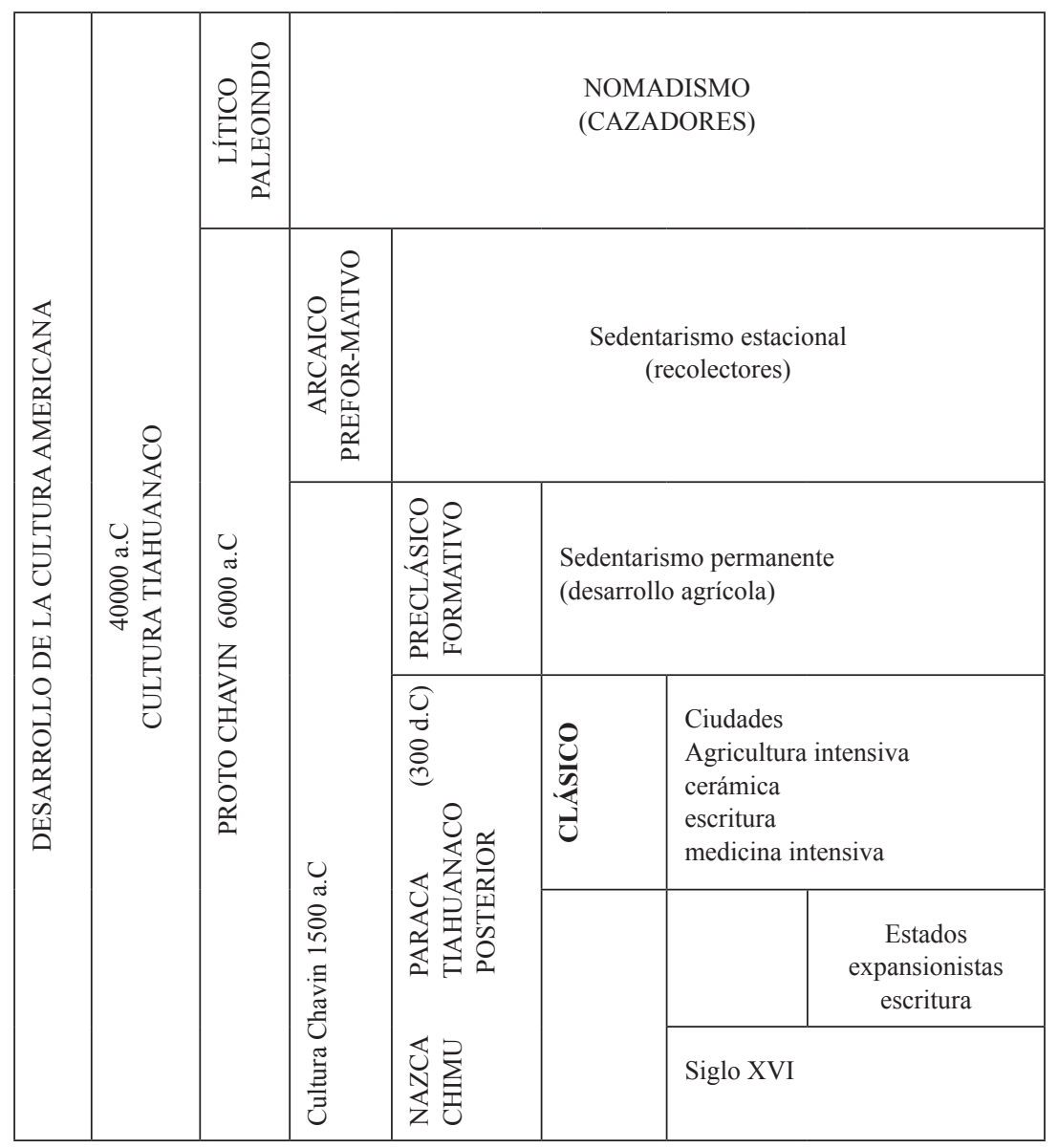

Tomado de A. Montenegro, Historia de A. L., 1976. Bogotá, respecto a las culturas precedentes o en evolución, posiblemente sean culturas epigonales del Tiahuanaco.

"En efecto, la cuenta del lago Titicaca está sembrada de ruinas más importantes, algunas de las cuales pertenecen a una fase arcaica de Tiwanaku... Es un complejo arquitectónico que aún no ha sido totalmente explotado y, a propósito del cual, sin que pueda explicarse muy bien porqué, se han tejido las interpretaciones más fantasiosas. ¿No se ha pretendido que Tiwanaku habia sido edificado por un pueblo procedente de otro plane$t a$, de Venus en particular, hace ya de ello 250 millones de años?" (Spanhni, 1979: 45-50). 
En suma, la historia andina es milenaria, los datos históricos, hasta ahora vistos, nos desafían a profundizar con mayor tiempo de dedicación y con recursos técnicos, humanos y materiales adecuados con miras hacia una sistematización más compleja.

Ahora entro netamente en la realidad socio-económica y política del pueblo andino en la época del Tawantisuyu. En primer término, como punto de referencia, veremos la cultura del imperio inkaiku, imperio que se caracterizo por su alta organización política dominante. No todo lo que leemos del Inkario, sino que, su representación máxima, depende de valores culturales que se remontan a miles de años, de culturas preinkaikas (la Tiwanaku, la Chavín, Nazca, Chimú, Mochica, etc.).

Montenegro expresó al respecto:

"La tercera gran región de América donde una alta cultura posclásica en la región andina, siglos antes habia Florecido la cultura Tiwanaku. Además en las costas peruanas se habian desarrollado también las culturas clásicas de las Mochicas, nazcas y chimúes. De todo este ambiente cultural propicio a la unidad se aprovechan los incas... resultaron en los Andes los herederos de culturas preexistentes." (Montenegro, 1976:29).
También Pons Muzzo agrega:

"Se considera al imperio de los incas como la sintesis de la cultura del Perú autóctono, porque los incas aprovecharon mucho de las formas culturales del Perú preincaico. Así, por ejemplo, el ayllu, la institución social por excelencia del imperio, se sabe que fue creación preincaica, la forma de trabajo común, el carácter agrícola de la cultura indígena, el sentido colectivista de la propiedad de la tierra.... Fueron por grupos preincaicos, y que después fueron aprovechados y perfeccionados por la sabiduría política de los Incas." (Muzzo, 1910:29).

El pueblo andino se define por ser una comunidad participativa, de servicio, de unidad, de identificación y la especificidad de su práctica es el "ayni" (solidaridad, reciprocidad, fraternidad); posee una economía complementaria y un sistema agrícola de pisos ecológicos en el anti plano frío, en el valle templado y en el trópico cálido.

En su sentido social, el "pueblo andino" es una sociedad del ayllu" que significa "sociedad comunitaria" en la que no se conocía la diferencia entre ricos y pobres, sencillamente porque los medios de producción estaban controlados bajo la filosofía del

1. El ayllu era una unidad familiar de 700 a 1000 personas que componían una pequeña comunidad incluyendo niños y adultos; es también división territorial de un cantón. 
ayni ${ }^{2}$, de producción y distribución según las necesidades de las familias de los ayllus. Pons Muzzo dice que en la sociedad andina:

"No existía la propiedad privada, las tres tierras de cultivo eran repartidas cada año entre todos los habitantes del Imperio para que cada uno tuviera lo necesario para su sustento; los bosques y los pastos guardados en almacenes especiales para el consumo de la casta civil y religiosa, y para alimentar al pueblo en las épocas de sequía, incendios, terremotos o guerras y para cuidar a los indígenas $y$ desvalidos..." (Muzzo, 1910:40).

La sociedad andina mantenían una alta norma de educación bajo los principios morales: "No robes, no mientas, no seas perezoso" $"$. Una infracción de estos principios era castigada incluso aniquilando al infractor (con garrote, con la horca o guindándolo ante el despeñadero). Realmente era una civilización de la ley rigurosa y cruel. Leicht nos da algunos casos de repudio y castigo:

"Muchas veces eran lanzados al mar los adúlteros... Se castigan asimismo severamente los delitos de homosexualidad, lo mismo que el aborto provocado y la mentira. Muy enérgicamente se castigaban también toda clase de delitos de robos y hurto. Aunque no se tratase sino de objetos de poco valor, se ahorcaba al ladrón; y cuando no era posible localizarlo inmediatamente, se plantaba en el centro de la calle una vara con ramas verdes, con lo cual se exhortaba a toda la población a darle caza. El que concedía cobijo a un ladrón, sufría la misma condena que este, y se le colgaba vivo de los dos pies hasta que estaba medio muerto, por pequeño que fuera el delito..." (Leicht, 1963:78).

Por eso, en lo que respecta al trabajo, la sociedad andina era una comunidad rígidamente trabajadora que, según la edad que se tenía, delegaba determinadas labores. El trabajo comunitario era el poder del gobierno, administrado bajo tres entes sociales: El emperador, los funcionarios de provincias y los ayllus. Jean Christian hace mención de cuáles eran las responsabilidades por edades:

"Hasta la edad de 9 años, el pequeno es libre de hacer lo que le guste. Lo más que se le pide, es ayudar a su padre o su madre en las labores domésticas. De los 9 a los 12 años el muchacho es enviado a los campos, a fin de vigilar las plantaciones de

\footnotetext{
2. Significa trabajo colectivo, sinónimo de solidaridad, reciprocidad, fraternidad.

3. Era el saludo cotidiano de los Incas.
} 
maíz (MAIZALES) y de alejar a las aves que atacan las mazorcas. De los 12 a los 20 años el joven pastorea las llamas en los pastizales y comienza a aprender el oficio (la hijita de 9-12 años tiene que cosechar las plantas utilizadas para teñir telas). En cuanto a la hija (de 12-20 años), se inicia en las diferentes formas de artesanía, así como en la elaboración de chicha de maiz, verdadera bebida nacional, utilizada en el transcurso de las fiestas. De los 20 a los 50 años, los indígenas adultos deben casarse. Hacia los sesenta tienen un mayor respeto como derecho, y se viene a consultarlos para que todo aquello tenga lugar en el desarrollo de la comunidad. Las mujeres envejecidas están encargadas con frecuencia, de la educación de los niños muy pequeños, del hilado y el tejido de lana" (Spanhni, 1979:79).

La economía andina estaba, y aún está basada, en un sistema de "propiedad del ayllu" o "propiedad comunitaria", que constituyen la tierra, los rebaños y el comercio recíproco. Muzzo dice al respecto:

"La estructura económica del Imperio de los Incas no era con miras al interés individual sino al interés social. La propiedad no era individual, es decir, no era de quien la poseía, la propiedad no tenía dueño, se usaba en función del interés social, y en relación con el trabajo. De nada le servía un individuo ser dueño de inmensas cantidades de tierras, sino las podía trabajar él...
La propiedad era usada en relación al interés social. Frente a los bienes no estaba el individuo, sino la sociedad y por lo tanto no hubo otro derecho que el interés social... la tierra no es materia de apropiación, y que, si es dividida, lo es en función del trabajo... la división de la tierra no tiene sino un carácter temporal, no es fija, definitiva, sino movible.

La propiedad pues, estaba en relación con el trabajo. El trabajo era considerado como una función social de la que no podía eximirse ningún individuo, era pues obligatorio..." (Muzzo, 1910,42-43).

En el pueblo andino los terrenos pertenecían al ayllu y servían de campos pastizales para el ganado y de cultivo agrícola. Por otro lado, había tierras comunitarias que eran distribuidas y usadas por las nuevas familias, incluso cuando no tenían casa donde habitar. El ayllu, a través del ayni, les ayudaba a edificar.

De esta manera, nadie sufría ni de hambre, ni de desempleo (las plagas actuales). Leicht nos expresa más claramente algunas de las acciones del trabajo comunitario, en lo que se refiere a trabajos en conjunto de los ayllus:

“...el momento en que habia de iniciarse la labor en los campos. En el día fijado, todos los hombres, las mujeres y los hijos mayores ya aptos para el trabajo, se congregaban para una pequeña ceremonia, que 
concluía en determinados cantos; tras de lo cual, se distribuían por sus diferentes lugares de trabajo.

Las distintas comunidades (ayllus) colaboran la dirección de uno de los cabezas de la familia: cuando una parcela estaba terminada, se iniciaba el trabajo en la siguiente, de acuerdo con una pauta determinada. Primero se cultivaban los campos tributarios, o sea aquellos cuya cosecha estaba destinada a los principes y sacerdotes; seguidamente los (terrenos) explotados en beneficio de la comunidad; $y$, por último, las tierras cuya producción se almacenaba como reserva para épocas de penuria y para ayudar a los convecinos afectados por alguna desgracia”. (Leicht, 1963:75).

En su sentido político, los gobernantes eran hereditarios según el sistema Inkario; los funcionarios de ayllus y markas, los jilakata y ma$1 \mathrm{ku}{ }^{4}$, eran elegidos por el ayllu en forma participativa y de turno comunal.

El gobierno no fue un imperio despótico, a pesar de imponer una disciplina férrea a sus súbditos y una obediencia sumisa de los mismos al Estado; los gobernantes del imperio se cuidaron del bienestar y de la salud de los gobernados. Muzzo dice que “el Imperio estableció un gobierno paternal y humanitario: cuidaron de los indigentes y de los desvalidos, $\mathrm{y}$ combatieron el hambre y la ociosidad". (Muzzo, 1910: 40).

El imperio incaico en relación con sus colonias, no representó a un destructor o saqueador, sino que fue preservador y perfeccionador (en el interior del imperio había decenas de pueblos colonizados). Leicht dice que las culturas colonizadas:

"eran las mismas que ordenaban sus asuntos internos, y nunca se interesaron los Incas por alterar los principios jurídicos que regulaban su vida familiar, y su régimen de propiedad y herencia, ni revolucionar cualquiera de los preceptos legislativos profundamente arraigados en el pueblo". (Leicht, 1963:78).

Al respecto Jean Christian Spanhni agrega que: “el Inca no atacó jamás su religión, ni sus costumbres, mucho menos sus más sagradas tradiciones; los exige únicamente pagar sus tributos y respetar al Sol de quien el mismo como Emperador, es el hijo indiscutible. La esclavitud es desconocida entre los Incas..." (Spanhni, 1979:88).

En suma: con todas estas características, el "pueblo andino" no es utópico ni exagerado; con razón los escritores lo calificaban llamándolo "comunismo primitivo", "Imperio

4. Jilakata, era autoridad-gobierno y jefe del ayllu. Se reconoce por su poncho, su lazo de cuero y su bastón. Es la autoridad de la administración indígena. Mallku era el gran jefe de marka. 
socialista" o propiamente "gobierno socialista". Todos estos adjetivos y otros merecen la sociedad andina por no existir la propiedad privada y porque las cosechas y los animales eran también propiedad comunal.

Hasta aquí hemos visto abreviadamente lo que se refiere a lo socioeconómico y político del hombre andino en sus épocas de Tiwanaku y Tawantisuyu.

Época propiamente colonial sobre la realidad socio-económica y política. Al pueblo andino le tocó vivir una etapa de explotación, de individualismo, de esclavitud, de masacre y muerte; verdaderamente fue un genocidio y etnocidio escandaloso jamás vivido en la historia andina. En realidad el tipo de vida impuesto por el colonizador europeo al estilo de saqueador y ladrón en nombre de Cristo, era la negación del modo de vida comunitario ancestral del pueblo andino. Duviols, en Revisionismo Histórico y Derecho Colonial en el siglo XVI, hace mención de dos destacados personajes que se expresaron respecto a la toma del poder del Inkario por los españoles: el dominico Francisco de Victoria, para quien no existe ninguna duda de que sus compatriotas se condujeron en Perú como agresores. Mucho más escandaloso es lo que él considera un hecho: que Atahualpa ya se había convertido en vasallo de la corona y que él había aceptado sus condiciones, ¡y ahora podía matarlo! He aquí algunas expresiones:

"Yo no entiendo la justicia de aquella guerra... nunca Atabaliba, ni los suyos habian hecho ningún agravio a los cristianos, ni cosa por donde lo debiesen hacer guerra... ni sé porqué pueden robar y despojar a los tristes de los vencidos de cuanto tienen y no tienen... Si los indios son hombres y prójimos". (Duvoils, 1977:27).

Por otro lado, la exposición de las casas, expresada después de la ejecución, era todavía más definida, pues Atahualpa era un señor natural ${ }^{5}$, injustamente ejecutado por los egresados que merecen el justo título y epíteto de tiranos:

"Sabe vuestra merced qué se dice de aquel gran rey del Perú, Atabaliba, que Pizarro tan tiránica y cruelmente despojó de su reino..." (Carta a un personaje de la calle, el 15 de octubre de 1535).

"Considérese aquí la justicia y título de esta guerra, la prisión de este señor y la sentencia y ejecución de su muerte, y la conciencia con que tienen aquellos tiranos tan grandes

5. El señor natural, ya sea rey o emperador, etc., es el que respeta lo que Santo Tomás llamaba la ley natural. Es decir la razón, la justicia, el orden, el bien común, como jefe toma medidas necesarias en beneficio de sus súbditos. En algunos casos es patriarcal y en otro elegido, comprometiéndose bajo juramento a la comunidad. 
tesoros, como en aquellos reinos a aquel rey tan grande $y$ otros infinitos señores y particulares robaron..." (Brevísima, 1552).

"Los españoles... entrados en el Perú, prendieron a un Señor natural de aquellos reinos, que se llamaba Atabaliba, sin dar el Atabaliba causa alguna para ello, sino que lo prendieron para matarle, a fin de poseer el reino del Perú más pacíficamente..." (Tratado de las doce dudas, ¿1662?) (Duvoils, 1977:28).

Con base en ella, Bonilla agrega:

"No cabe la mínima duda de que el nacimiento del problema indígena, tanto en Mesoamérica como en la Región Andina, fue una consecuencia directa de la conquista y la colonización que España impuso en esta región desde los inicios del siglo XVI. Antes de 1532 ciertamente hubo muchas etnias, pero su existencia no constituía "problema". Aunque existieron etnias, no había indios. El "indio" fue una palabra inventada para designar y sobre todo excluir al integrante de la sociedad sojuzgada, al sobreviviente de uno de los tremendos genocidios demográficos que la historia registra". (Bonilla, 1988:88)

Los españoles establecieron su centro de administración en México y en América Andina, principalmente en el Perú. El opropio y el avasallamiento en los aborígenes fue letal en esta región. Los datos que nos llegan para hoy no compaginan, en lo que se refiere a la matanza de aborígenes, producto del trato inhumano que recibieron. Sin embargo, se tiene una aproximación de 20 millones durante la colonia, que murieron impositivamente, con excepción del resto del continente. Por otro lado, la destrucción (el etnocidio) de los valores culturales de las etnias.

El pueblo andino en la sociedad colonial verdaderamente sufrió un trastorno y una deformación total en su realidad socio-económica y política. Se intentó borrar su imagen e identidad.

Socialmente, se le degrada del "ser humano" a un "ser animal", y no era más que una bestia de carga. Jean Christian describe algunas expresiones referidas a la aborigen en aquel momento:

"Los conquistadores clasifican ¡más de animales que de seres humanos!, ;más cerca del mono que el hombre! aseguran otros.

¿Es verdad para los doctores de la iglesia, la cualidad de ser humano no pertenece sino únicamente a los cristianos. Ahora bien, estos naturales de las tierras lejanas no parecen poseer ninguna de las virtudes que hacen de un hombre, un perfecto discipulo de Cristo!

Los miembros influyentes del clero mezclan sus voces para declarar que: los indios son bestias inferiores a los negros, enemigos de la verdad, mentirosos por excelencia, a tal punto ique el testimonio de ellos 
vale tanto como el de un blanco!". (Spanhni, 1979:126-127).

Económicamente, el pueblo andino no gozó absolutamente de beneficios. Todas las modalidades de trabajo anteriores a la época de Tiwanaku y Tawantisuyu fueron convertidas por los españoles en ventaja de ellos. Bonilla comenta aquella situación así:

"La puesta en marcha de la colonización, significó básicamente la convención de esta economía agraria tradicional en una economía fundamentalmente minera, en respuesta a las exigencias de la acumulación primitiva del capital.

La mercantilización creciente de la economía colonial, terminó por romper el aislamiento de la población nativa y por alterar de manera significativa el modelo especial que la metrópoli impuso... Además al interior de regiones ahora segmentadas como consecuencia del propio proceso de la sociedad colonial, el control de los recursos estratégicos y de los medios de producción a los propietarios, respecto a quienes contaban para su sobrevivencia con la sola venta de su fuerza de trabajo. Y subordinó esta dimensión en la conciencia de opresores $y$ oprimidos al mantenimiento de la dialéctica colonizador y colonizado", (Bonilla, 1988:90-91).

La sociedad andina no existió para el colonizador, solo fueron esclavos y bestias de carga. Para llevar a cabo esta acción se decretaron leyes opresivas y de exterminio aborigen, a través de trabajos forzados. La situación de aquel momento la tenemos según Christian:

"Los indios son agrupados en reservas, "reducciones" de 400 a 500 individuos. La reserva es vigilada por el mayordomo y el sacerdote que son todos poderosos. Las reservas están sometidas a una jurisdicción muy severa, concebidas para evitar a los indígenas vivir en comunidad en un lugar determinado con el fin de facilitar su evangelización. Cualquier abuso o infracción eran castigados... son castigados los insolentes, los que no se presentan a su trabajo (aunque estén enfermos) y aquellos quienes prolonguen sus horas de descanso. Son asimismo castigados quienes no dan ofrendas a los santos, quienes no reciten el rosario, los que no van a la misa (era tomada lista en el templo el que falta no importa la distancia). Son obligados a arrodillarse cada vez que suena la campana de la iglesia. Con multas y latigazos, se castiga a quienes reciben en su casa o mesa a una mujer de costumbres ligeras. Ninguna mujer o viuda menor de 50 años debe servir de beber a un hermano, a un cuñado, a un tío o a un primo. Ningún cacique puede ofrecer un techo a una hermana, a una cuñada, a una tía o a una prima menor de 50 años. Los jefes de comunidades, quienes no fomenten el matrimonio de una hija o a las segundas nupcias de una viuda son castigados, porque son acusados de querer aprovecharse de 
las personas en cuestión. Los juegos de dados y naipes están prohibidos. Ninguna diversión podrá ser organizada sin el previo consentimiento del sacerdote, igualmente se trata de una fiesta de familia. Ningún indio puede abandonar su reserva para establecerse en otra reducción a menos que esté en posición de una licencia especial, otorgada por el virrey" (Spanhni, 1979:120-121).

En el drama se ve el rico y el mendigo lázaro, las autoridades (el virrey, el mayordomo, el alcalde y el sacerdote) en las reservas llevan una vida principesca, mientras que el aborigen e indígena desnutridos, harapientos, tristes, resignados, ven cerrarse, para siempre, las puertas de la libertad.

La conquista es acompañada de hambre, las pérdidas de las tradiciones, introducción de enfermedades desconocidas por el pueblo sufriente y el homicidio.

Se impuso la encomienda política de tributo del indígena al emperador. Esta se convierte en la forma absoluta de explotación de los oprimidos, porque los que se resisten son decapitados. Al hablar de encomendadores $^{6}$, Christian Spanhni cita en su libro -Los indios de los andes-, a Felipe Guaman Poma de
Ayala (escritor del siglo XVI sobre la masacre aborigen) que hace una descripción importante:

"Los indios tienen que servir como laborantes, palafreneros, jardineros, pastores y como bestias de carga. Las mujeres de los encomendadores son aun peores que sus maridos. Reclaman a los indigenas maiz, papas, corderos, gallinas, huevos, trigo y frutas, pimienta y sal, grasa, manteca y otros productos alimenticios, sin contar perdices y hierbas aromáticas... los encomendadores, exigen que los indigenas le ceden ganado, el cual dan a cambio de vino, los obligaban a fabricar lazos, telas, vestiduras y no los dejan entrar a su casa ni de día ni de noche, y no les reconocen salario alguno". (Spanhni, 1979:136).

Los trabajos forzados comprenden: el cultivo intensivo de la coca, en regiones tropicales e insalubres, la fabricación de cierta cantidad de objetos de uso doméstico y, sobre todo, la peligrosa faena de las minas. Los yacimientos se encuentran en la Cordillera de los Andes, de 4000 y 5000 m de altitud en Huancavelica, sobre territorio peruano y en la región Potosí en Bolivia. Otro testimonio de inhumanidad de carácter dramático y de dolor (en las minas) es la descripción siguiente:

6. Personaje directo de la corona, propuesto para la vigilancia de un poblado, teniendo incluso que cobrar los tributos y de beneficiarse de las prestaciones de servicios gratuitos.

El poblado más o menos de 100000 a 150000 personas, el encomendado además tenía leyes que ejecutar, y las ponía al doble (representaba lo despótico y lo tiránico). 
"El calvario comienza ya desde la partida, porque el reclutamiento se hace por la violencia. El viaje dura varias semanas, durante las cuales numerosos indigenas caen enfermos y son abandonados a su triste suerte, otros sucumben y sus cadáveres cubren el sendero. Algunos van acompañados de sus mujeres e hijos, quienes vencidos por la privación mueren en el camino.

La tarea en las minas es inhumana. No se detiene ni de día ni de noche, obligando a los indígenas a contratar ayudantes. Las compras de candelas para alumbrarse en las galerías, corre a cargo de los obreros. Los indígenas, tratados como esclavos, atormentados de deudas, no pueden ni siquiera soñar en abandonar la mina. Y se aprovechan de su ausencia para apoderarse de sus tierras.

Los mineros no disponen de casas. Son obligados a instalarse en un lugar que ocupan las bestias, desprovistos de techo en donde por la noche el frío es intenso. Cuando la estación de lluvias, estos recintos se convierten en verdaderas cloacas. La higiene no existe, la promiscuidad es absoluta. Es en estos precarios refugios donde las inmundicias se acumulan, donde los obreros y sus familias se retiran, curando las llagas y tratando de encontrar algún reposo.

Los indios hacen cualquier cosa para escapar al reclutamiento. Unos venden sus bienes e intentan comprar su libertad. Otros, se mutilan voluntariamente, o alquilan a sus mujeres e hijos a fin de sustraerse al calvario. Los jefes de comunidades son martirizados si no entregan el contingente de mineros impuesto por los españoles. Numerosos indigenas prefieren suicidarse junto a sus familias, antes que ser enviados a una mina. Los demás, los MITAYOS, son encadenados y parten, sin esperanzas de retorno, en medios de gritos de desesperación de sus parientes y amigos". (Spanhni, 1979: 124).

El pueblo andino fue tal como se refiere Bonilla al decir "fue un sistema socio-político y económico que fuera la expresión del dominio de la minoría y que específicamente excluyera la participación de los indios" (Bonilla, 1988:93). Las consecuencias fueron la destrucción de los valores culturales, la suplantación de la adoración de la religión católica con un trato imperativo e inhumano. Prohibían las fiestas propias del pueblo, portar vestiduras tradicionales, la música, la danza y las canciones, pues no eran otra cosa que un atropello total. En este caso las "reducciones" sirvieron para la degradación letal de los aborígenes. Ese espíritu de la opresión no concluye en la colonia, sino que continúa en la época republicana con la diferencia de que quien lo ejerce ha cambiado su turno.

El pueblo andino en la época republicana. Después de la colonia española, sigue esclavo del 
neo-colonialismo, "todo blanco es, más o menos, un Pizarro, un Valverde o un Areche (Bonilla, 1988:97). Se asiste al nacimiento del gamonalismo, es decir, el acaparamiento fraudulento de tierras. En efecto, es fácil hacer renuncias a los derechos a los aborígenes.

A pesar de ser los aborígenes los legítimos propietarios de sus tierras, sin embargo, han sido despojados de sus pertenencias y hasta de su propia identidad así como Bonilla expresa: "La dominación política establecida por la burguesía de este periodo, revistió una forma oligárquica, es decir, un grupo de familias aristocráticas, al mismo tiempo que recortaba el espacio político de las clases populares." (Bonilla, 1988:101).

Favre agrega que:"Las grandes masas demográficas que podrían alimentarlo se encuentran todavía establecidas en el interior andino, controladas por las viejas aristocracias terratenientes que las dominan con su poder colonial". (Favre, 1988:116).

$\mathrm{Si}$ bien la independencia reconoce jurídicamente al indígena, en realidad no le aporta liberación económica ni social, sino que lo siguen manteniendo en su condición servil, marginado y colonizado.

Desde la óptica de la sociedad actual, el pueblo andino y su realidad socio-económica y política pertenecen a un aparato que tiene repercusiones mundiales. El pueblo andino está inmerso en una sociedad que define la libertad individual del capitalismo y de la propiedad privada, y su especificidad de práctica por el "máximo beneficio", característica que viene alimentando y sosteniendo desde el colonialismo.

El mundo está compuesto por una dialéctica de: ricos y pobres, opresores y oprimidos, desarrollados y subdesarrollados. Esta división no posee puntos iguales en lo que se refiere al término demográfico mundial. Ya somos 6770 millones de habitantes en la actualidad (Estadísticas Mundiales,2009). De los que el $80 \%$ sucumbe en la pobreza, el $15 \%$ es clase media y el $5 \%$ es clase rica (Jorge Pixley-Clodovis Boff, 1986:17-20). Son estratos que responden, por lo menos, a tres causas principales:

a. El legado colonial ${ }^{7}$.

7. Por lo menos desde la realidad de América Latina, tenemos legados irradicables. Una de las herencias de las colonias en nuestra actualidad bien podríamos decir que es el egoísmo; cada uno acapara para uno, aunque al otro lo veamos tirado, decimos: ¡Muérete por tonto! Esto es manifestado a nivel personal, y a nivel de gobierno. Al asumir el gobierno (sea provincial o nacional), aprovecha para enriquecerse y el pueblo cada vez más queda con la misma desesperanza y el racismo, etc. Por ejemplo, el término "indio" o "indígena" es netamente inventado y producto de la colonización. 
b. Lo geopolítico de los dos superpoderes del planeta ${ }^{8}$.

c. La mala distribución de las riquezas (Laborem Exercens, 1981: 16-18).

Las consecuencias se pueden calificar como las más atroces del siglo, en la crítica situación socioeconómica de los pobres, privados de las necesidades básicas: alimento, vivienda, salud, educación, empleo y participación social. Y el escándalo resulta aún mayor porque la pobreza aumenta en categorías astronómicas mientras exista "una minoría rica de un gran confort y abundantes lujos por la concentración de la riqueza". (Gaudium et spes, 1965: 63).

Al respecto, Santa Ana comenta:

"Los recursos mundiales y el crecimiento económico están controlados, por una combinación de mecanismos sociales, económicos, políticos y culturales, que a su vez son manipulados por unos pocos sectores poderosos de la sociedad en su propio beneficio (nacional e internacional)." (Santa Ana, 1986:117).

Las estructuras neo-coloniales y las corporaciones transnacionales pretenden ayudar a resolver los problemas de los pueblos pobres, pero ellos se presentan para explotar los recursos de la tierra y emplear mano de obra barata. No resuelven el problema del desempleo y empobrecen el ambiente natural, "mientras dejan de lado la necesidad de distribución equitativa de los beneficios entre todos los sectores sociales." (CMI, 1975:3).

Los mecanismos dominantes crean y consolidan la pobreza y surgieron como parte del proceso histórico. La mayoría se desarrollaron en los últimos cinco siglos, especialmente en el periodo de la expansión colonial occidental y sobre todo desde la revolución industrial. Este proceso de dominación actuó progresivamente como una particular estructura sobre todos los seres humanos y sus relaciones, en todas partes. Dentro de esta estructura socio-económica, se desarrolla una nueva relación de seres humanos orientada a la acumulación privada de la riqueza y los bienes. Se produce dominación y dependencia, pobres y ricos, opresores y oprimidos.

Por otro lado, sobre el libre comercio internacional, los mecanismos

8. Es un término que descansa y desarrolla en categorías de poder y espacio, desde la época de la postguerra entre USA y la URSS, ahora ex URSS. Al respecto Helio Gallardo tiene una rica información en su artículo "Tres formas de Lectura de los Fenómenos Políticos Latinoamericanos", Revista PASOS del DEI -N²4, Julio-Agosto 1989. Asimismo en su libro Elementos de Política de América Latina pp. 121-242. También José Comblin "Doctrina de Seguridad Nacional I", pp. 30-50. Y la Encíclica Sollicitudo Rei Socialis 11-26. 
reguladores del libre mercado se han convertido en imperativo, de parte de los ricos. De ahí que la dependencia ya es fenómeno estructural.

La trasferencia tecnológica y militarizada a las naciones pobres, se da por la imposición del tecnicismo y la geopolítica de los dos superpoderes: "los poderosos económicos determinan las prioridades de las áreas de crecimiento económico, como los precios más altos para ellos y para los explotados sobre los más bajos" (Laborem Exercens, 1967: 17. Populorum Progressio, 1981:57-59).

La consecuencia es la creciente marginación de los pobres, cuyos efectos socio-económicos son profundamente escandalosos, características claramente definidas en cualquier país situado en la órbita de la pobreza, donde el pobre es víctima de la injusticia institucional, local e internacional, la que produce: analfabetismo, violencia, deuda externa, éxodos masivos por cuestiones políticas, racismo, etnocidio y genocidio.

Dentro de este panorama mundial, el pueblo andino se encuentra inmerso en lo que ahora son aproximadamente 28 millones de personas (CELADE, 1985: 15). Una población pobre que es el mundo aborigen, aplastado por una estructura socio-económica-política tan egoísta y despótica.

El pueblo andino, en un proceso de genocidio y etnocidio inhumano, ha sabido conservar un remanente con actitudes libertarias, desde la opresión colonial. Ha conservado y proclamado el espíritu comunitario y sus elementos culturales ancestrales que son indelebles. Cunill hace mención:

"En estas regiones serranas las antiguas costumbres perviven con fuerza. Continúa el predominio de la alimentación de productos andinos precolombinos como la quínoa, la papa, el cacao, el chuño, el charqui; se mantiene el hábito de masticar la coca. Sigue el trabajo como sistema de mutuas prestaciones y el trabajo colectivo de forma de minga, fajina o faena, para diversas obras de interés comunitario... y practicas litúrgicas al Dios que les liberta, Pachamama". (Cunill, 1978:75).

Los signos libertarios se han dado en el trayecto de los cinco siglos como un modelo ideológico de reivindicación comunitaria. Se mantienen Tupac Amaru y Tupac Katari, jefes de las celebres rebeliones de los Ayllu Marka en el pueblo andino del siglo XVIII.

Si el ayllu marka es producto de la relación colonial y el indigenismo ${ }^{9}$

9. El indigenismo se perfila como un artificio del grupo dominante que, con el pretexto de integrar culturalmente al indígena, en realidad continúa dominándolo económica y políticamente. El indígena jamás se ha sentido reflejado en este discurso cultural que el otro tiene acerca de él y de ahí el fracaso de esta astucia. 
una treta de la sociedad dominante, cuyo poder se sostiene manteniendo la estructura colonial, la indianidad expresa, por el contrario, el deseo de romper con esta relación colonial para su reivindicación como una etnicidad. Las resistencias pasivas, movimientos mesiánicos, rebeliones y revueltas armadas que fueron apareciendo desde el principio de la conquista, ilustran esta larga lucha del hombre andino en contra de la opresión y la dominación. Si bien es cierto que estas formas de resistencia dejan y siguen dejando saldos de muertes y de represiones muy duras, las luchas continúan hoy. Un tipo de esto es el "SENDERO LUMINOSO", no importa cómo y qué colorido político le den, pero lo importante $\mathrm{y}$ digno de saber es que obedece a raíces de completa marginación por el gobierno peruano. La zona donde nace este grupo guerrillero es la zona más empobrecida del país. Se tuvo la esperanza, con la política agraria de Juan Velasco (1968), de que los campesinos recibirían su parcela de tierra; sin embargo, las recuperaron los latifundistas.

Uno de los problemas sociales de grandes proporciones es la marginación del aborigen, a pesar que ya desde la década del 70 se han producido simposios y movimientos de organización en pos de una recuperación por la destrucción de las civilizaciones amerindias que denuncian el genocidio y etnocidio.
Aun cuando esta destrucción no se detiene, sino que más bien se acelera, como sucede en Brasil, el Paraguay, los años 70 se caracterizaban en numerosos países de América Latina por el nuevo planeamiento que se hace en torno a la "cuestión indígena". La reivindicación de la "Indianidad" es manifestación de este despertar indígena en lo particular en América Andina.

En Barbados se dieron dos simposios de alta trascendencia. Mientras que al primero acudieron profesionales deseosos de concienciar a la opinión internacional acerca de la muerte física y cultural de las sociedades amerindias, en el segundo tomaron la palabra los "actores", o sea los dirigentes de los diferentes movimientos en distintas épocas a lo largo de los cinco siglos de opresión y dominación. Ello, al mismo tiempo que reivindicaban su especificidad étnica, afirmaban su indianidad, y herencia colonial que hoy sirve para movilizar a los vencidos de antaño y que constituía el emblema de su lucha común de liberación.

En efecto, esta "cuestión indígena" no es un problema reciente. Nace con la conquista, se desarrolla durante todo el periodo colonial y evoluciona a lo largo de más de siglo y medio de vida republicana, siguiendo los contextos nacionales, así que ninguna política logra resolverlo.

Todo este montaje de indigenismo ha permitido que el amerindio 
permanezca en una perpetua marginación y, más aún, tildándolo de salvajismo y barbarie, signo de lo que hoy tiene atrasada a la América Latina Andina. La realidad es todo lo contrario y falso porque: "Quienes acusan a los indígenas, dan prueba de una hipocresía desconcertante. Olvidan que las naciones de la religión han surgido y se han organizado sin la participación de los indígenas, quienes siempre han sido mantenidos al margen de los asuntos del país."( Spanhni,1979:351).

Así es como hemos visto el panorama del proceso histórico del pueblo andino, un pueblo aborigen, sufrido y creyente, digno de repensar su problemática a la luz de la esperanza de liberación, en la perspectiva del Reino de Dios.

\section{Conclusión}

En relación con el pueblo andino en el contexto histórico de opresión y la liberación, deseamos recordar tres aspectos importantes: Primero, el pueblo andino es un pueblo con un pasado brillante en su etapa primigenia. Todos sus aspectos son vistos bajo el esquema comunitario "El Ayllu Marka". Ya en su etapa colonial es impuesto el tiranismo que rompe todo el esquema comunitario pero el pueblo andino se resistió. La historia lo prescribe como la época de genocidio y el etnocidio, que llegó a ser un pasado muy triste y oscuro que vivió nuestra América andina; los signos morales, económicos, sociales y culturales permanecen hoy como ejes dañinos para nuestra sociedad. Sin embargo, pese al genocidio y etnocidio, pudo permanecer el remanente andino que no ha sido borrado sino que permanece intacto en cuanto a los signos comunitarios $\mathrm{y}$ religiosos que se vivieron en aquel momento y permanecen aún hoy.

\section{Bibliografía}

\section{Libros:}

Aguiló, Federico. (1988).Tipología Religiosa Andina. La paz Cochabamba: Editorial Los Amigos del Libro.

Albo, Xavier (recopilador). (1988). Raíces de América: El mundo Aymara. Madrid: Alianza Editorial-América.

Arthur Soldan/R.G. Pennance (copiladores). (1975). Diccionario de Economía. Barcelona: Ediciones Oikos-tau, S.A.

Centro de Estudios Peruanos. (1982). Historia de los Cajamarquinos. Lima: CEP.

Clevolet, Michel.( 1982). Lectura Materialista de la Biblia. Salamanca: Ediciones Sígueme.

Consejo Mundial de Iglesias. (1982). Venga tu reino: Perspectivas Misioneras. Salamanca: Ediciones Sígueme.

Comblin, José. (1988). Doctrina de seguridad Nacional I. San José: Editorial Nueva Década.

Concejo Nacional de Población. Perú: (1984). Hechos y Cifras Demográficos. Lima: CEP. 
Centro de Información de Estudios y Documentación (1981) Acerca de la Historia y el Universo Aymara. Lima: CIED.

Centro Latinoamericano de Demografía, CELADE. 1985

Cunill, Pedro. (1978). La América Andina. España: Editorial Ariel

(1985) Diccionario Teológico del Nuevo Testamento. Salamanca: Ediciones Sígueme.

Duviols, Pierre. (1977). La Destrucción de las Religiones Andinas: Durante la conquista y la colonia. México: Universidad Autónoma de México.

Eliade, Mircea. (1970). Tratado de la Historia de las Religiones. Madrid: Ediciones Cristiandad.

Flor G. Serrano/Alonso Shokel. (1979). Diccionario Terminología de Ciencia Bíblica. Madrid: Ediciones Cristiandad.

Fierro, Alfredo. (1979). Teoría de los Cristianismos. Buenos Aires: Ediciones Aurora.

Gallardo, Helio. (1986). Elementos de Política en América Latina. San José: DEI.

Gutiérrez, Gustavo. (1982). La fuerza Histórica de los Pobres. Salamanca: Ediciones Sígueme.

Gutiérrez, Gustavo. (La teología Política en el Perú del Siglo XVI). (1982). Allpanchis: El Cristianismo Colonial. Cuzco: Instituto de-Pastoral Andina.

Gerardi, Emilio. (1988) La conquista de América. ¿Con qué derecho? San José: DEI.

Hanks, Tomas. (1982). Opresión Pobreza y Liberación: Perspectivas Bíblicas. Editorial Caribe.
Instituto Interamericano (Varios escritores). (1988). Indianidad Etnocidio e Indigenismo en América Latina. México: Coedición del Center de Estatus Mexicaines et Centre americaines y el instituto Indigenista Interamericano.

Johannes, B. Bauer. (1967). Diccionario de Teología Bíblica. Barcelona: Editorial Herder.

Jorge Pixley/Clodovis Boff. (1986). Opción por los pobres. España: Ediciones Paulinas.

Jeremías, Joachim. (1985). Jerusalén en Tiempos de Jesús. Madrid: Editorial Cristiandad.

Leicht, Hermann.(1963). Arte y Cultura Preincaicas. Madrid: Ediciones Aguilar S. A.

Mason, J. Alden. (1961). Las Antiguas Culturas del Perú. México: Fondo de Cultura Económica.

Metraux, Alfred. (1975). Los Incas. Buenos Aires: Centro Editorial de América Latina.

Montes Ruiz, Fernando. (1984). La Máscara de Piedra: Simbolismo y Personalidad Aymara en la Historia. La Paz: Editorial Quipus- Comisión Episcopal de Educación.

Montenegro, Augusto. (1976). Historia de América Latina. Bogotá: Editorial Norma. Monast, J.E. (1972). Los Indios Aimaraes: ¿Evangelizados o Solamente Bautizados? Buenos Aires: Ediciones Carlos Cohlki.

Marty, E. Martin. (1987). Peregrinos en su Propia Tierra. Bilbao: Editorial Deselie de Brouwer, S. A.

Nelson Wilton M (editor). (1974). Diccionario Ilustrado de la Biblia. Miami Florida: Editorial Caribe. 
Otero, Gustavo A. (1975). Vida Social en el Coloniaje. La paz: Biblioteca del Sesquicentenario de la República.

Peter Waldwann/Ulrich Zelinsky. (1984). América Latina: Síntesis Histórica, Política, Económica y Cultural. Barcelona: Ediciones Herder.

Pons Muzzo, Gustavo. (1910). Historia del Perú. Lima: Editorial Universo S. A.

Posnansky, Arthur. (1945). Tiahuanaco: Cuna del Hombre Americano. New York: Editor J. J. Agustín.

Richard, Pablo (editor). (1981). Historia de la Teología en América Latina. San José: DEI-CEHILA.

Richard, Pablo. (1987). La Fuerza Espiritual de la Iglesia de los Pobres. San José: DEI.

Rostworoweky de Diez Canseco, María. (1988). Estructuras Andinas del Poder. Lima: Instituto de Estudios PeruanosIEP Ediciones.

Spanhni, J. Cristhian. (1979). Los Indios de los Andes. Guatemala Editorial Piedra Santa.

Santa Ana, Julio de. (1985). El Desafio de los Pobres a la Iglesia. San José: Editorial EDUCA.

Sánchez, Luis Alberto. (1975). América PreColombina, Descubrimiento y Colonización. Madrid: EDAF.

Schurer, Emil. (1979). Historia del Pueblo Judio en Tiempos de Jesús. Madrid: Ediciones Cristiandad.

Talmez, Elsa. (1985). Santiago: Lectura Latinoamericana de la Epístola. San José: DEI.

Varios. (1974). Antropología e Indigenismo. San José: CEDAL (Seminarios y documentos).
Waisbarb, Simone. (1979). Tiahuanaco. (10 mil enigmas incas). México: Editorial Diana.

Yoder, John H. (1985). Jesús y la Realidad Politica. Buenos Aires: Ediciones Certeza.

\section{Revistas}

Gallego, Epifanio. "Mundo y Reino, Ayer y Hoy". En Revista de Teología Bíblica y $\mathrm{Fe}$. Madrid: Edit. Biblia y Fe. Setiembrediciembre de 1989. Vol. XV, No. 45. 54-72 pp.

Gallardo, Helio. "Tres formas de Lectura de los Fenómenos Políticos Latinoamericanos". En Revista PASOS. San José: DEI, Julio-Agosto de 1989. No, 23115 pp.

Hinkelanmert, Franza. "Economía y Teología: Las Leyes del Mercado y la Fe". En Revista PASOS. San José: DEI, Mayo-Junio de 1989, No. 2318 pp.

Laureano, Andrés. "El Tercer Mundo, Hoy Problemática Humana”. En Revista de Teología Bíblica-Biblia y Fe. Madrid: Edt. Biblia y Fe, Setiembre-diciembre de 1989. Vol., XV, No. 45 94-109 pp.

Saulnier Ch/Rolland B. Palestina en Tiempos de Jesús. Cuadernos Bíblicos. No. 27, Estela Navarra: Verbo Divino, 1986. 62 pp.

\section{Internet y cartas y encíclicas}

http://www.exitoexportador.com/stats.htm

Juan Pablo II, Carta Encíclica. Sollicitudo rei Socialis. 30 de diciembre de 1987.

Juan Pablo II, Carta Encíclica. Laborem Excercens. 14 de setiembre de 1981.

Pablo VI, Carta Encíclica. Gaudium et Spes. 7 de diciembre de 1965.

Pablo VI, Carta Encíclica. Populorum Progressio. 26 de marzo de 1967. 


\section{Documentos inéditos}

Aguilar, Rodrigo. "Construyendo el Reino de Dios en el Compromiso Revolucionario Nicaragüense" SIMPOSIO: Impresiones de Nicaragua. Costa Rica. UNA-Escuela Ecuménica de Ciencias de la Religión. 13 de setiembre de 1989.
Consejo Mundial de Iglesias. La Iglesia y los Pobres. Nairobi: CMI, 1975.

Comblin, José. Valoración Cristiana de las Religiones Nativas o Sincretismo Religioso. Oruro-La Paz s. f.

Sierro, Alfredo. Teoría de los Cristianismos. San José: CECODERS (fotocopia) s.f. 
